\title{
ANALISIS PERCEPATAN TANAH MAKSIMUM DENGAN MENGGUNAKAN RUMUSAN ESTEVA DAN DONOVAN (Studi Kasus Pada Semenanjung Utara Pulau Sulawesi)
}

\author{
Cloudya Gabriella Kapojos ${ }^{1)}$, Gerald Tamuntuan ${ }^{1)}$, Guntur Pasau ${ }^{1)}$ \\ ${ }^{1)}$ Program Studi Fisika FMIPA Universitas Sam Ratulangi Manado \\ e-mail: cloudyagabriella@gmail.com; gtamuntuan@gmail.com; pasaujunior@gmail.com
}

\begin{abstract}
ABSTRAK
Telah dilakukan analisis percepatan tanah maksimum di semenanjung utara Pulau Sulawesi dengan menggunakan rumusan Esteva dan rumusan Donovan. Data yang digunakan adalah data gempa bumi tektonik yang terjadi di sekitar semenanjung utara Pulau Sulawesi pada periode tahun 2008 - 2014. Hasil analisis menunjukkan bahwa perubahan nilai percepatan tanah dari rumusan Esteva dan rumusan Donovan memiliki pola perubahan yang sama terhadap jarak. Nilai percepatan tanah menurut rumusan Donovan lebih tinggi dibandingkan dari rumusan Esteva. Perbandingan dengan data akselerograf mengindikasikan bahwa rumusan Esteva lebih cocok digunakan dalam mengestimasi percepatan tanah maksimum di semenanjung utara Pulau Sulawesi. Hasil pemetaan sebaran percepatan tanah maksimum menunjukkan bahwa wilayah Kabupaten Minahasa Utara berada pada zona dengan resiko yang lebih tinggi dibandingkan wilayah lainnya di semenanjung utara Pulau Sulawesi.
\end{abstract}

Kata Kunci :Percepatan tanah maksimum, gempa bumi, semenanjung utara Pulau Sulawesi

\section{ANALYSIS OF PEAK GROUND ACCELERATION USING ESTEVA AND DONOVAN FORMULATIONS (A Case Study On The Northern Part of Sulawesi)}

\begin{abstract}
Peak ground acceleration on the northern part of Sulawesi Island has been analysis by using Esteva and Donovan formulations. We use tectonic earthquake data that occurred around the northern part of Sulawesi Island during period of 2008 till 2014. The results showed that both Esteva and Donovan formulations have the similar pattern on changes of peak ground acceleration to the distance. Value of peak ground acceleration calculated with Donovan method higher than Esteva method. Comparison between empirical formula results and accelerograf data show that Esteva formulation more suitable for use in estimating the peak ground acceleration in the northern part of Sulawesi Island. Distribution of peak ground acceleration indicate that the earthquake impact on North Minahasa Regency is higher than other regions in northern part of Sulawesi island.
\end{abstract}

Keynotes: Peak Ground Acceleration, Earthquake, Northern Part of Sulawesi Island

\section{PENDAHULUAN}

Gempabumi merupakan salah satu fenomena fisis yang terjadi sebagai akibat dari pergerakan lempeng-lempeng bumi ataupun proses vulkanik. Gempa bumi sering menyebabkan kerusakan-kerusakan pada daerah ataupun disekitar tempat terjadinya. Sulawesi Utara merupakan kawasan dengan intensitas gempa bumi yang relatif tinggi sehubungan dengan posisi geografisnya yang di daerah pertemuan lempeng Filiphina dan Eurasia dengan lempeng Pasifik (Pasau dan Tanauma, 2011; Putra dkk, 2012). Salah satu faktor yang dapat menentukan besar-kecilnya kerusakan sebagai akibat dari gempa bumi adalah percepatan tanah maksimum atau peak ground acceleration (PGA) (Edwiza, 2008). 
Percepatan tanah maksimum merupakan indikator percepatan tanah yang terjadi disuatu tempat akibat gempa bumi dan dapat diketahui melalui dua cara yaitu pengukuran dengan menggunakan alat accelerograph dan melalui pendekatan empiris (Linkimer, 2008). Beberapa metode yang bisa dipakai untuk menentukan nilai percepatan tanah maksimum secara empiris yaitu metode Richter, Fukushima-Tanaka, Donovan, Esteva, Murphy-O'brein, Mc.Guirre, dan Kanai (Macropoulos, 1985; Edwiza dan Novita, 2008). Informasi tentang nilai percepatan tanah maksimum dan pola sebarannya merupakan sesuatu yang penting diketahui dalam perencanaan serta pembangunan infrasutruktur tahan gempa. Dengan mengetahui sebaran atau variasi nilai percepatan tanah maksimum disuatu wilayah, maka dapat dipetakan lokasi-lokasi yang rawan mengalami kerusakan ketika terjadi gempa bumi.

Semenanjung utara Pulau Sulawesi yang meliputi beberapa kabupaten/kota seperti Minahasa, Minahasa Selatan, Minahasa Tenggara, Minahasa Utara, Manado dan Bitung merupakan daerahdaerah yang sedang giat-giatnya membangun. Pemetaan nilai percepatan tanah maksimum tentunya akan menjadi informasi penting dalam menunjang pembangunan pada daerahdaerah tersebut. Dalam penelitian ini disajikan analisis percepatan tanah maksimum di wilayah semenanjung utara Pulau Sulawesi dengan menggunakan rumusan empiris Esteva dan Donovan.

\section{TINJAUAN PUSTAKA}

\section{Parameter Gempabumi}

Setiap kejadian gempabumi akan menghasilkan informasi seismik berupa rekaman sinyal berbentuk gelombang yang setelah proses manual atau non manual akan menjadi data. Informasi seismik selanjutnya mengalami proses pengumpulan, pengolahan dan analisa sehingga menjadi parameter gempa bumi. Parameter gempabumi tersebut meliputi :

1. Waktu terjadinya gempa

2. Episenter

3. Kedalaman (Hiposenter)

4. Magnitudo

5. Intensitas

\section{Percepatan Tanah Maksimum}

Parameter getaran gelombang gempa yang dicatat oleh seismograf umumnya adalah simpangan kecepatan atau velocity dalam satuan kine $(\mathrm{cm} / \mathrm{dt})$. Selain velocity tentunya parameter yang lain seperti displacement (simpangan dalam satuan micrometer) dan percepatan (acceleration dalam satuan gal atau $\mathrm{cm} / \mathrm{dt}^{2}$ ) juga dapat ditentukan. Parameter percepatan gelombang seismik atau sering disebut percepatan tanah merupakan salah satu parameter yang penting dalam seismologi teknik atau earthquakes engineering. Nilai percepatan tanah dapat dihitung langsung dengan seismograf khusus yang disebut strong motion seismograph atau accelerograf. Namun karena begitu pentingnya nilai percepatan tanah dalam menghitung koefisien seismik untuk bangunan tahan gempa, sedangkan jaringan accelerograf tidak lengkap baik dari segi periode waktu maupun tempatnya, maka perhitungan empiris sangat perlu dibuat.

Oleh sebab itu untuk keperluan bangunan tahan gempa harga percepatan tanah dapat dihitung dengan cara pendekatan dari data historis gempabumi (Ibrahim dan Subardjo, 2005). Beberapa formula pendekatan antara lain :

\section{Rumusan Esteva}

$$
a=\frac{5600 \exp ^{0.5 \cdot M}}{(r+40)^{2}}
$$

Dimana :

$\mathrm{a}=$ Percepatan tanah pada tempat yang akan dicari.

$\mathrm{M}=$ Magnitudo

$\mathrm{r}=$ Jarak hiposenter (dalam satuan $\mathrm{km})$

2. Rumusan Donovan

$$
a=\frac{1080 \exp ^{0,5 M}}{(R+25)^{1.32}}
$$

Di mana a adalah percepatan, $M$ adalah magnitude dan $r$ adalah jarak hiposenter dalam satuan $\mathrm{km}$.

$$
\begin{aligned}
& \mathrm{R}=\text { jarak hiposenter }(\mathrm{km}) \\
& R=\sqrt{\Delta^{2}+h^{2}} \ldots \ldots \ldots \ldots \ldots \ldots(3) \\
& \begin{array}{c}
\Delta=\text { jarak episenter }(\mathrm{km}) \\
\mathrm{h}=\text { kedalaman sumber gempa }(\mathrm{km})
\end{array}
\end{aligned}
$$




\section{METODE PENELITIAN}

Penelitian ini menggunakan data gempa bumi dari BMKG. Data yang digunakan adalah data gempa bumi disekitar semenanjung utara Pulau Sulawesi pada periode tahun 2008 2014. Data dianalisis dengan menggunakan dua rumusan empiris yaitu rumusan Esteva dan rumusan Donovan dan selanjutnya dibandingkan dengan hasil pengukuran alat akselerograf. Pada bagian akhir dilakukan pemetaan sebaran nilai percepatan tanah maksimum menggunakan rumusan Esteva dan Donovan untuk mengetahui peta potensi resiko bencana gempa bumi di semenanjung utara Pulau Sulawesi yang diakibatkan oleh percepatan tanah.

\section{HASIL DAN PEMBAHASAN}

\section{Pola nilai percepatan tanah maksimum terhadap perubahan jarak}

Untuk mengetahui bagaimana pola perubahan nilai percepatan tanah maksimum terhadap jarak maka telah dilakukan perhitungan nilai percepatan tanah maksimum bergantung jarak dengan menggunakan rumusan empiris Esteva dan Donovan. Pada Gambar 1 dan 2 menunjukan perubahan nilai percepatan tanah maksimum pada gempa dengan magnitudo $7.8 \mathrm{SR}$ dan 6.4 SR. Jarak $0 \mathrm{~km}$ dalam hal ini merujuk pada episenter gempa.

Nilai percepatan tanah maksimum berdasarkan rumusan Donovan terlihat relatif lebih tinggi dibandingkan dengan rumusan Esteva. Grafik dari kedua rumusan tersebut membentuk pola yang semakin menurun seiring bertambahnya jarak. Pada perbedaan magnitudo gempa 7,8 SR dan 6,4 SR, nilai percepatan tanah maksimum berdasarkan rumusan Esteva maupun Donovan mengalami penurunan yang sangat signifikan yaitu masing-masing $50.24 \%$ pada rumusan Esteva dan 50.23\% pada rumusan Donovan.

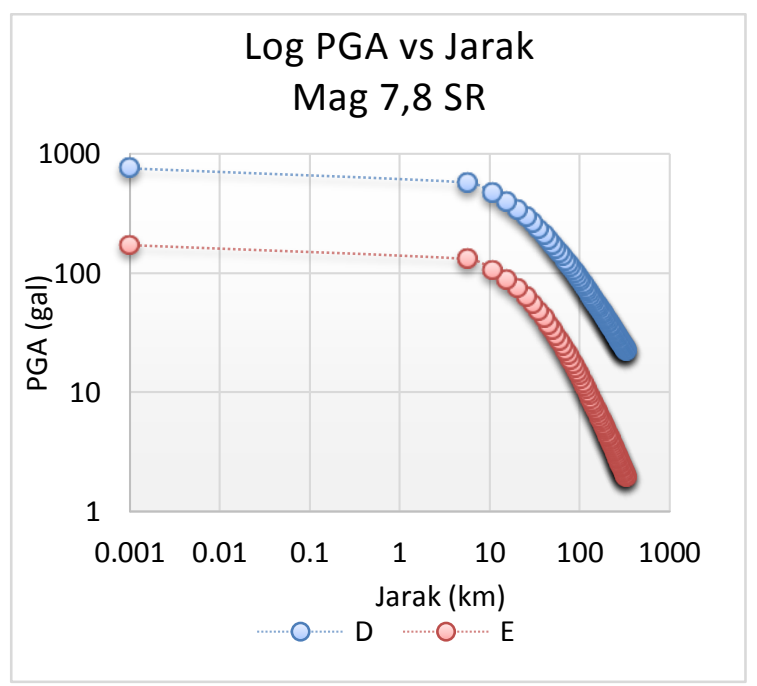

Gambar 1. Grafik Percepatan tanah maksimum terhadap jarak episenter yang dihitung menggunakan rumusan empiris pada kasus gempa 7,8 SR

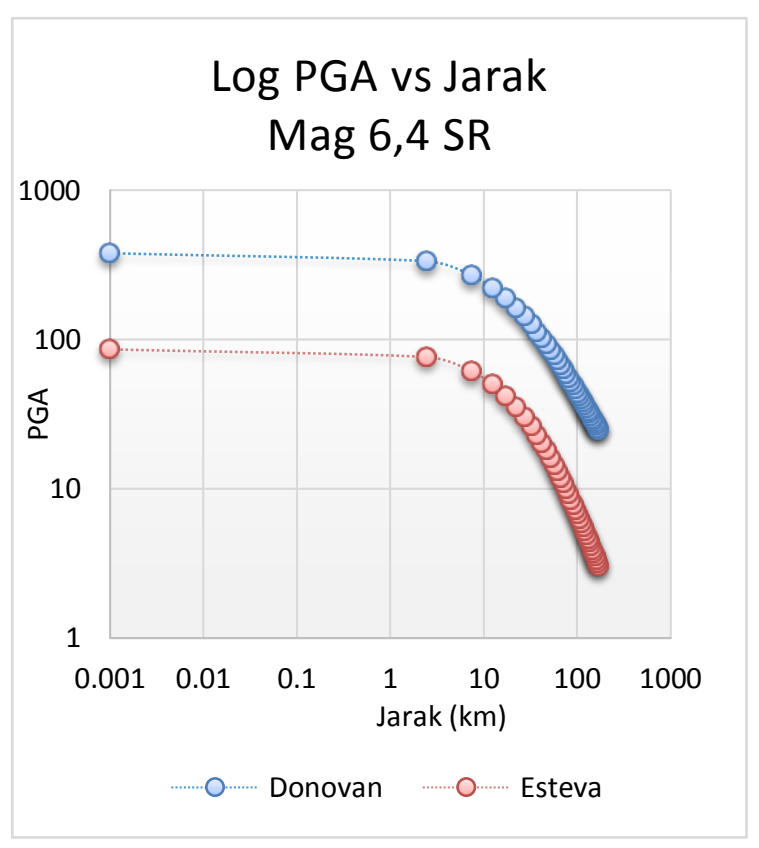

Gambar 2. Grafik percepatan tanah maksimum terhadap jarak yang dihitung menggunakan rumusan empiris pada kasus gempa 6,4 SR

\section{Perbandingan nilai perhitungan percepatan tanah menggunakan rumusan empiris dengan hasil pengukuran alat akselerograf}

Kesesuain hasil-hasil perhitungan dan pengukuran percepatan tanah pada semenanjung utara Pulau Sulawesi dapat dilihat pada Gambar 3 dan 4. Dalam hal ini 
data gempa bumi yang digunakan mulai adalah data pada tahun 2008-2011 dengan magnitudo antara 2 hingga 7,8 SR. Posisi acuan dalam proses perhitungan dengan rumusan empiris adalah posisi stasiun tempat alat akselerograf berada yaitu di Kota Manado. Berdasarkan grafik pada gambar 3 dan 4 terlihat bahwa hasil perhitungan percepatan tanah menggunakan rumusan Esteva relatif lebih mendekati nilai hasil pengukuran alat ukur akselerograf jika dibandingkan dengan hasil perhitungan dengan rumusan Donovan. Hal ini mengindikasikan bahwa rumusan empiris Esteva lebih cocok digunakan dalam mengestimasi percepatan tanah maksimum di semenanjung utara Pulau Sulawesi.

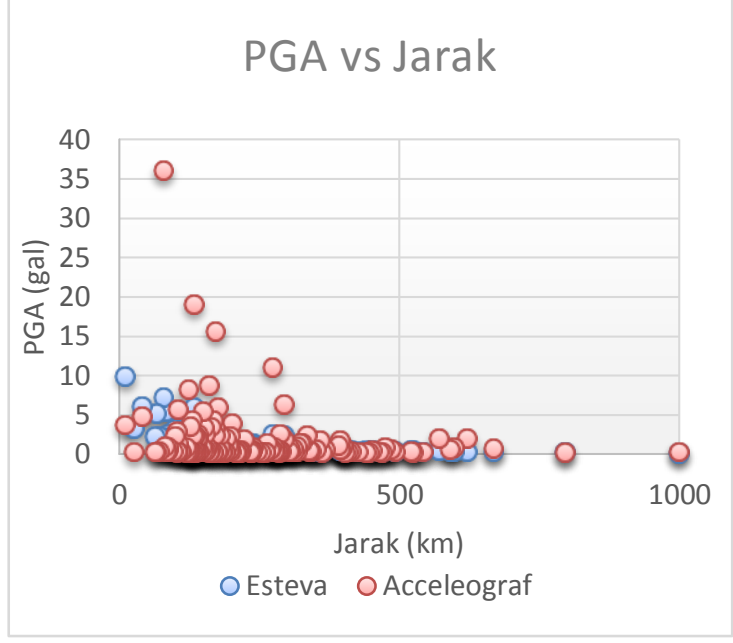

Gambar 3. Grafik PGA hasil perhitungan dengan menggunakan rumusan esteva dan PGA dari alat akselerograf terhadap jarak.

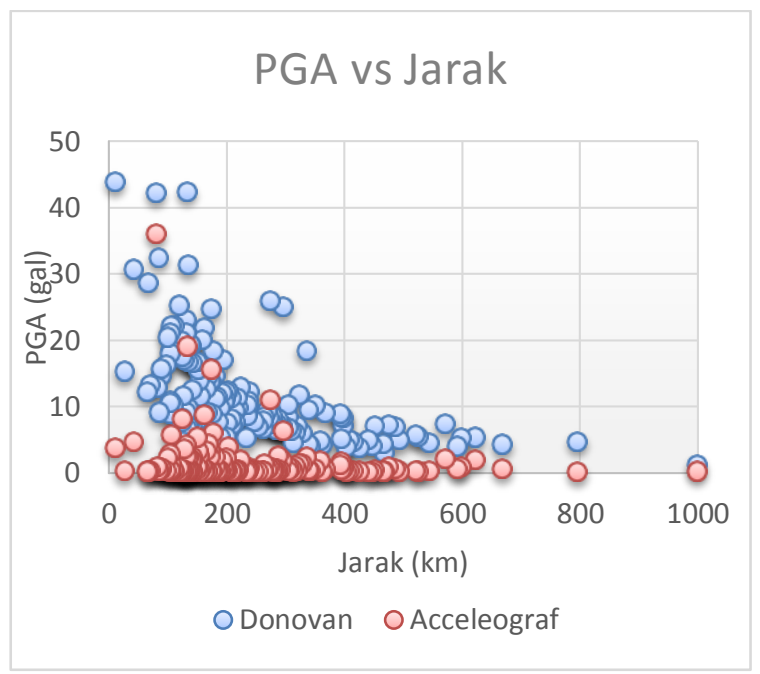

Gambar 4. Grafik PGA hasil perhitungan dengan menggunakan rumusan Donovan dan PGA dari alat akselerograf terhadap jarak.

\section{Estimasi Pola Sebaran Percepatan Tanah Maksimum di Semenanjung Utara Pulau Sulawesi}

Pemetaan pola sebaran percepatan tanah maksimum di semenanjung utara Pulau Sulawesi dalam penelitian ini menggunakan data magnitudo enam gempa yang terjadi disekitar wilayah tersebut. Keenam gempa tersebut merupakan gempa-gempa tektonik pada periode antara tahun 2008 hingga 2014 dan memiliki magnitudo paling besar. Percepatan tanah maksimum dihitung pada setiap grid sebesar $0,1^{\circ} \times 0,1^{\circ}$ yang diplot pada lintang $0^{\circ} 30^{\prime}-2^{\circ} 30^{\prime}$ LU dan $124^{\circ} 00^{\prime}-125^{\circ} 30^{\prime} \mathrm{BT}$.

Gambar 5 dan 6 masing-masing menunjukkan pola sebaran percepatan tanah maksimum dalam bentuk kontur sebagai hasil rumusan dari Esteva dan Donovan. Berdasarkan rumusan Esteva diperoleh bahwa percepatan tanah maksimum di semenanjung utara Pulau Sulawesi bervariasi antara $1-10$ gal. Nilai percepatan tanah tertinggi, yaitu 10 gal, berada pada daerah paling utara dari semenanjung utara Pulau Sulawesi yang merupakan lokasi dari Kabupaten Minahasa Utara. Nilai percepatan tanah terendah, yaitu 1 gal, berada pada sebagian dari wilayah Kabupaten Minahasa Tenggara. Dari pemetaan yang dibuat berdasarkan rumusan Esteva secara umum besar percepatan tanah pada kabupaten/kota di semenanjung utara Pulau Sulawesi secara berurut dari yang paling tinggi adalah Kabupaten Minahasa Utara, Kota Bitung, Kota Manado, Kabupaten Minahasa, Kabupaten Minahasa Selatan dan Kabupaten Minahasa Tenggara.

Peta percepatan tanah maksimum berdasarkan rumusan Donovan memiliki pola yang relatif sama dengan hasil rumusan Esteva. Perbedaan yang mencolok hanya terdapat pada pola sebaran percepatan tanah terendah. Pada rumusan Donovan, percepatan tanah terendah yaitu sebesar 11 gal tersebar relatif luas meliputi beberapa wilayah Kabupaten Minahasa, Minahasa Selatan, dan Minahasa Tenggara. Nilai percepatan tanah tertinggi tetap berada pada wilayah utara Kabupaten Minahasa Utara yaitu sekitar 60 gal. Besar nilai percepatan tanah maksimum ini tentunya erat kaitannya dengan dampak yang diperoleh ketika terjadi gempa bumi. Wilayah-wilayah dengan nilai percepatan 
tanah maksimum yang lebih besar dapat diartikan sebagai wilayah yang lebih rawan dibandingkan dengan wilayah-wilayah dengan nilai percepatan tanah yang lebih kecil.

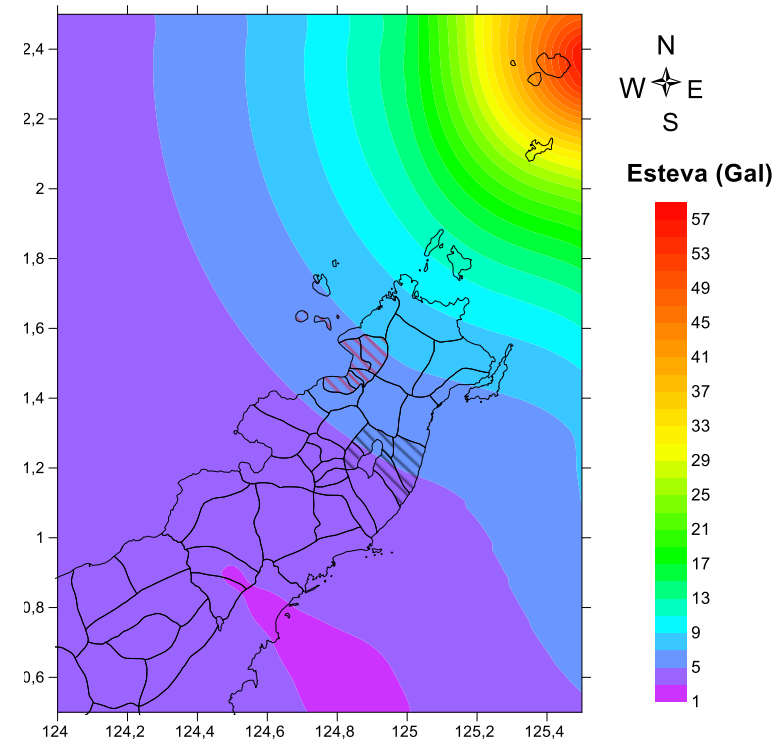

Gambar 5. Peta kontur percepatan tanah maksimum menggunakan rumusan Esteva.

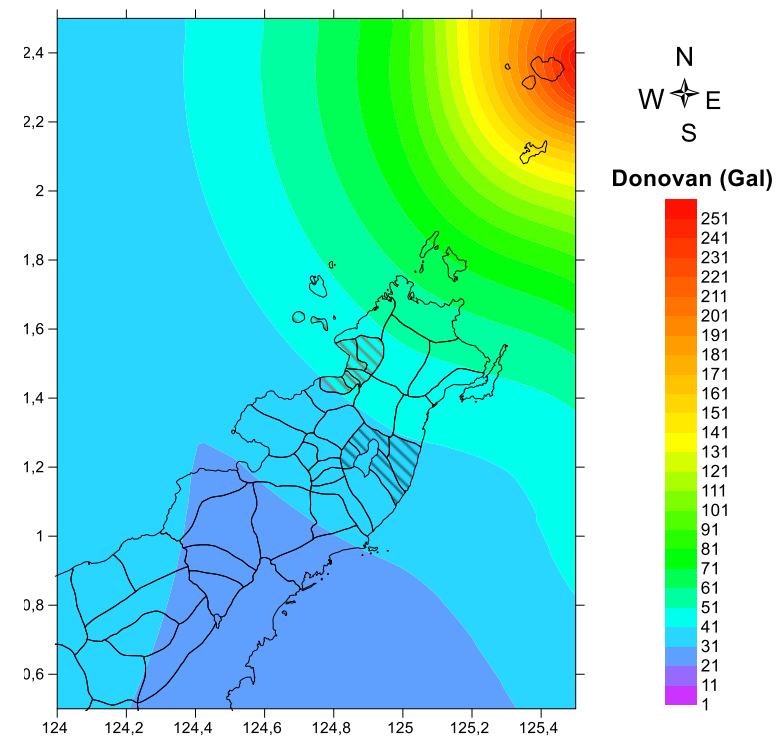

Gambar 6. Peta kontur percepatan tanah maksimum menggunakan rumusan Donovan

\section{KESIMPULAN}

Dari hasil analisis percepatan tanah maksimum di semenanjung utara Pulau Sulawesi dapat diperoleh beberapa kesimpulan sebagai berikut:
1. Percepatan tanah maksimum sebagai hasil perhitungan dengan menggunakan rumusan Donovan relatif lebih tinggi jika dibandingkan dengan rumusan Esteva. Namun demikian perubahan nilai percepatan tanah maksimum terhadap jarak dari kedua rumusan ini menunjukkan pola yang relatif sama.

2. Rumusan Esteva merupakan rumusan empiris yang lebih cocok dalam mengestimasi nilai percepatan tanah maksimum di semenanjung utara Pulau Sulawesi jika dibandingkan dengan rumusan Donovan.

3. Pemetaan sebaran nilai percepatan tanah maksimum menunjukkan bahwa wilayah bagian utara Kabupaten Minahasa Utara merupakan daerah yang relatif lebih rawan terhadap dampak gempa bumi gerakan tanah jika dibandingkan dengan daerah lainnya di semenanjung utara Pulau Sulawesi. Sementara wilayah yang relatif paling kecil resikonya adalah wilayah Kabupaten Minahaa Tenggara.

\section{DAFTAR PUSTAKA}

Edwiza dan Novita. 2008. Pemetaan Percepatan Tanah Maksimum Dan Intensitas Seismik Kota Padang Panjang Menggunakan Metode Kanai. Jurnal Geofisika No. 29 Vol.2.ISSN: 0854-8471. Hal: 111-118

Edwiza. 2008. Analisis Terhadap Intensitas dan Percepatan Tanah Maksimum Gempa Sumbar.No.29 Vol.1 Thn. XV. ISSN: 0854-8471. Hal: 73-79

Ibrahim dan Subardjo. 2005. Pendahuluan Seismologi. Meteorologi, Klimatologi dan Geofisika. Jakarta

Macropoulos. 1985. Seismic Hazard In Greece. Ii. Ground Acceleration. Tectonophysics, 117.Hal :259-294

Pasau, G., dan Tanauma, A., 2011. Pemodelan Sumber Gempa Di Wilayah Sulawesi Utara Sebagai Upaya Mitigasi Bencana Gempa Bumi. Jurnal Ilmiah Sains Vol. 11 No. 2. Hal: 202209

Putra, R., Kiyono, J., Ono, Y., Parajuli, H., 2012. Seismic Hazard Analysis For 
Indonesian. Journal of Natural Disaster Science, No. 2 Volume 33.Hal : 59-70

Linkimer. 2008. Relationship Between Peak Ground AccelerationAnd Modified
Mercalli Intensity In Costa Rica. Revista Geológica de América Central, 38ISSN: 0256-7024. Hal : 81-94 